\title{
Expresión de la Interleucina 10 (IL-10) y el Factor de Crecimiento Transformante Beta (TGF-ß) en Mucosa Intestinal de Crías de Alpaca (Vicugna pacos)
}

\author{
Interleukin 10 (IL-10) and Transforming Growth Factor Beta (TGF- B) \\ Expression in Intestinal Mucosa of Alpaca Crias (Vicugna pacos)
}
Cesar Burga C. ${ }^{1}$, Alberto Manchego S..$^{1,3}$, Gina Castro S. ${ }^{1}$, Giovanni Pérez G. ${ }^{2}$, Mercy Ramírez V. ${ }^{1}$, Nieves Sandoval C. ${ }^{2}$

\section{Resumen}

\begin{abstract}
El objetivo del trabajo fue evaluar los niveles de expresión relativa de los genes de las citoquinas IL-10 y TGF- $\beta$ en la mucosa intestinal de alpacas de 2 a 47 días de edad, clínicamente sanas. Se formaron tres grupos etarios (seis crías por grupo) conformados por alpacas de 2 a 8 días (grupo 1), 10 a 21 días (grupo 2) y 26 a 47 días (grupo 3), sin distinción de sexo o raza. Se tomó la porción media del yeyuno de cada animal, se extrajo el ARN total y se empleó la técnica RT-PCR en tiempo-real con cebadores específicos para las citoquinas en estudio. La expresión relativa de ARNm de IL10 y TGF- $\beta$ fue determinada por el método comparativo $2^{-\Delta \Delta} \mathrm{Ct}$ usando como calibrador el yeyuno de tres fetos de 11 meses de gestación y como gen endógeno el gliceraldehído-3-fosfato deshidrogenasa (GAPDH). La expresión promedio de ARNm de IL-10 fue de 7.21 1.02 (grupo 1), 13.53 \pm 1.26 (grupo 2) y 18.77 \pm 1.48 (grupo 3) veces lo expresado por el grupo calibrador, mostrando diferencia significativa $(\mathrm{p}<0.05)$ entre grupos etarios. La expresión promedio de ARNm de TGF- $\beta$ fue de $2.18 \pm 0.23$ (grupo 1), $3.03 \pm 0.18$ (grupo 2 ) y $4.06 \pm 0.15$ (grupo 3) veces lo expresado por el grupo calibrador, mostrando diferencia significativa $(\mathrm{p}<0.05)$ entre grupos etarios. La expresión de ARNm de IL-10 y TGF- $\beta$ fue dependiente de la edad, incrementándose significativamente con la mayor edad de las crías.
\end{abstract}

Palabras clave: IL-10, TFG-â, T regulador, alpaca, intestino, RT-PCR tiempo real

${ }^{1}$ Laboratorio de Microbiología y Parasitología Veterinaria, ${ }^{2}$ Laboratorio de Histología, Embriología y Patología Veterinaria, Facultad de Medicina Veterinaria, Universidad Nacional Mayor de San Marcos, Lima, Perú

${ }^{3}$ E-mail: amanchegos@gmail.com

Recibido: 5 de octubre de 2016

Aceptado para publicación: 2 de febrero de 2017 
The aim of the present study was to evaluate the relative expression levels of cytokines IL-10 and TGF- $\beta$ in the intestinal mucosa of clinically healthy alpacas from 2 to 47 days old. The animals were classified in three age groups (six animals per group): 2-8 days old (group 1), 10-21 days old (group 2) and 26-47-days old (group 3), regardless sex or breed. The midportion of jejunum of each animal was collected; total RNA was extracted and then analyzed by real-time RT-PCR technique using IL-10 and TGF- $\beta$ specific primers. The relative mRNA expression analysis was done using the comparative $2-{ }^{\Delta \Delta} \mathrm{Ct}$ method. Glyceraldehyde-3-phosphate dehydrogenase (GAPDH) was used as housekeeping gene and jejunum of three 11-month-old fetuses were used as calibrators. The results showed that IL-10 mRNA expression levels were 7.21 \pm 1.02 (group 1), 13.53 \pm 1.26 (group 2), and $18.77 \pm 1.48$ (group 3 ) times as expressed by the calibrate group with significant difference between age groups $(\mathrm{p}<0.05)$. Also, TGF- $\beta$ mRNA expression levels were $2.18 \pm 0.23$ (group 1), $3.03 \pm 0.18$ (group 2), and $4.06 \pm 0.15$ (group 3) times as expressed by the calibrate group with significant difference between age groups $(\mathrm{p}<0.05)$. The expression of IL-10 and TGF- $\beta$ mRNA was age dependent, increasing significantly in older animals.

Key words: IL-10, TFG-â, T regulator, alpaca, intestine, real time RT-PCR

\section{INTRODUCCIÓN}

Las células $\mathrm{T}$ de la mucosa intestinal logran mantener un balance entre la tolerancia y la respuesta inflamatoria, discriminando entre microorganismos patógenos, microorganismos saprófitos y antígenos inocuos propio de la dieta alimenticia (Harrison y Powrie, 2013).

Las células T reguladoras controlan las respuestas inmunes a nivel intestinal a través de la producción de IL-10 y TGF- $\beta$. Estas citoquinas son producidas principalmente por los diferentes grupos de células $\mathrm{T}$ reg como Th3, Tr1 o nTreg (Curotto de Lafaille y Lafaille, 2009); no obstante, TGF- $\beta$ también es producido por enterocitos y células presentadoras de antígenos (Biancheri et al., 2014) e IL-10 por casi todos los leucocitos (Saraiva y O'Garra, 2010). Estas citoquinas regulan la respuesta inflamatoria a través de muchas funciones como la inhibición de la diferenciación a otros linajes de células $\mathrm{T}$ (Th1, Th2 y Th17), generación de más células $\mathrm{T}$ reg, inhibición en la producción de citoquinas pro inflamatorias (IL1, IL-2, IL6, IL12, IFN- $\gamma$, IL-4 e IL-17), producción de citoquinas antiinflamatorias (IL-10 y TGF- $\beta$ ), estimulación de la producción de IgA por células B y la inhibición, tanto de la expresión del MHC-II, como de las moléculas coestimuladoras en células presentadoras de antígenos (Spits y de Waal Malefyt, 1992; Konkel y Chen, 2011).

En la mucosa intestinal de las alpacas se ha determinado la expresión de los genes de las interleucinas TNF $\alpha$ e IL1 $\alpha$ (Bardález et al., 2013), y en leucocitos circulantes de alpacas adultas se ha determinado el incremento de la expresión del gen de la IL10 cuando son estimulados in vitro con antigenos clostridiales (Watanabe et al., 2014).

Teniendo en cuenta la importancia de estas citoquinas en el equilibrio intestinal, el presente trabajo busca describir la cinética de expresión del ARNm de IL-10 y TGF- $\beta$ en la mucosa yeyunal de alpacas, con la finalidad de identificar los roles del sistema inmune en la defensa del organismo y adaptación de su entorno en los primeros 47 días de vida, periodo de gran susceptibilidad a enfermedades con altas tasas de mortalidad (Ameghino y DeMartini, 1991). 


\section{Materias y MéTOdos}

\section{Animales y Lugar de Ejecución}

Se seleccionaron 21 alpacas clínicamente sanas, sin considerar sexo o raza, de la estación experimental del Instituto Veterinario de Investigaciones Tropicales y de Altura (IVITA), localizada en el distrito de Maranganí, provincia de Canchis, departamento de Cusco, Perú. El IVITA es parte de la Universidad Nacional Mayor de San Marcos (UNMSM). La fase de campo se desarrolló entre enero y marzo de 2014.

El rebaño de alpacas de la institución fue criado en condiciones semiextensivas, con alimentación al pastoreo. El estudio fue realizado en épocas de parición y empadre, condicionando una alta circulación de animales por la monta y estrés fisiológico de madres y crías. Además, el periodo de muestreo coincidió con la temporada alta de lluvias, favoreciendo el crecimiento de los pastos y la proliferación de potenciales patógenos productores de enfermedades entéricas (Rosadio et al., 2012), que podían ser ingeridos por las alpacas neonatas.

El estudio fue aprobado por el Comité de Ética y Bienestar Animal de la Facultad de Medicina Veterinaria (FMV) de la UNMSM.

\section{Diseño Experimental}

Se designaron tres grupos etarios de seis alpacas cada uno. Grupo 1 constituido por alpacas de 2 a 8 días de edad, grupo 2 por alpacas de 10 a 21 días de edad y grupo 3 por alpacas de 26 a 47 días de edad. Cada grupo estuvo conformado por 6 animales. Se tuvo un grupo control $(n=3)$, constituido por fetos de alpaca de 11 meses de gestación, exentos de estímulos de la inmunidad pasiva maternal y factores del medio ambiente. Este grupo control fue usado como calibrador para el análisis de expresión de genes $2^{-\Delta \Delta} \mathrm{Ct}$ (Livak y Schmittgen, 2001).

\section{Muestras y Obtención de Ácidos Nucleicos}

Los animales fueron manejados bajo el protocolo de Autorización N. ${ }^{\circ} 2009-001$ del Comité de Ética y Bienestar Animal de la Facultad de Medicina Veterinaria de la UNMSM. Para el sacrificio de los animales se empleó $1.5 \mathrm{mg} / \mathrm{kg}$ de xilacina (Rompun ${ }^{\circledR}$ ) y $7.5 \mathrm{mg} / \mathrm{kg}$ de ketamina (Vetalar $\left.{ }^{\circledR}\right)$, vía intramuscular, seguido por una sobredosis de $50 \mathrm{mg} / \mathrm{kg}$, vía endovenosa, de pentobarbital sódico (Halatal $\left.{ }^{\circledR}\right)$.

Se tomó una porción de $2 \mathrm{~cm}$ de longitud del yeyuno de cada animal y feto. Estos segmentos fueron lavados con suero fisiológico al $0.9 \%$ para retirar contenido intestinal y fueron almacenados en nitrógeno líquido $\left(-196{ }^{\circ} \mathrm{C}\right)$.

Las muestras fueron procesadas en el Laboratorio de Microbiología de la FMVUNMSM. Se utilizó TRIzol® Reagent (ThermoFisher Scientific, EEUU) y el kit PureLink ${ }^{\text {TM }}$ Micro-to-Midi System (Invitrogen $^{\mathrm{TM}}$, EEUU), siguiendo las indicaciones del fabricante, para la extracción del ARN total. Posteriormente, se empleó el kit Quant-iT ${ }^{\mathrm{TM}}$ RNA HS (Invitrogen, EEUU) y el fluorómetro Qubit® (ThermoFisher Scientific, EEUU), siguiendo las indicaciones del fabricante, para cuantificar el ARN y poder aislar $1 \mu \mathrm{g}$ de ARN total.

Para la obtención del ADNc se empleó el kit SuperScript ${ }^{\mathrm{TM}}$ III First-Strand Synthesis SuperMix for qRT-PCR (Invitrogen, EEUU), siguiendo las indicaciones del fabricante.

\section{Elección de Oligonucleótidos}

Se diseñaron los oligonucleótidos cebadores con base de secuencias de alpaca publicadas en el Genbank usando el programa Primer3 output (www.primer3.com) y el programa BLAST del NCBI (www.ncbi. nlm.nih.gov/blast/) (Cuadro 1). 
Cuadro 1. Oligonucleótidos empleados en la RT-PCR Tiempo-Real para los genes de GAPDH, IL-10 y TGF- $\beta$ de alpacas

\begin{tabular}{ccccc}
\hline Gen & $\begin{array}{c}\text { Producto } \\
(\mathrm{pb})^{1}\end{array}$ & $\begin{array}{c}\text { Secuencia de oligonucleotidos } \\
\left(5^{\prime}-3^{\prime}\right)^{2}\end{array}$ & Acceso Genbank & $\mathrm{Tm}^{3}$ \\
\hline GAPDH & 201 & F: ATCACTGCCACCCAGAAGAC & XM_006210852.1 & 60.12 \\
& & R: GCACGTCAGATCCACAACAG & & 60.32 \\
IL-10 & 205 & F: TTACCTGGAGGAGGTGATGC & XM_006215461.1 & 60.07 \\
& & R: GGCTTTGTAGACCCCCTTCT & & 59.58 \\
TGF- $\beta$ & \multirow{2}{*}{185} & F: GAGGTGATCTYGCCACCATT & NM_001290071.1 & 59.93 \\
& & R: GTCCTTGCGGAAGTCAATGT & & 60.12 \\
\hline
\end{tabular}

\footnotetext{
${ }^{1} \mathrm{~Pb}$ : longitud del producto expresada en pares de bases

${ }^{2}$ Los iniciadores se expresan como $\mathrm{F}$ (cebador de avance) y $\mathrm{R}$ (cebador de regreso)

${ }^{3} \mathrm{Tm}$ : Temperatura de melting o hibridación de los oligonucleótidos cebadores
}

\section{PCR Tiempo Real}

Se empleó el kit SYBR ${ }^{\circledR}$ GreenER ${ }^{\mathrm{TM}}$ qPCR Super Mix Universal (Invitrogen, EEUU), siguiendo las indicaciones del fabricante. Asimismo, se empleó el termociclador Applied Biosystem ${ }^{\circledR} 7500$ real-time PCR System con el siguiente protocolo: 1 ciclo de $50{ }^{\circ} \mathrm{C}$ por 2 min (incubación de UDG), 1 ciclo de $95^{\circ} \mathrm{C}$ por $10 \mathrm{~min}$ (inactivación de UDG y activación polimerasa), seguido de 40 ciclos de $95^{\circ} \mathrm{C}$ por $15 \mathrm{~s}$ (denaturalización), $60{ }^{\circ} \mathrm{C}$ por $60 \mathrm{~s}$ (hibridación y extensión) y lectura de placa. La temperatura de melting o curva de disociación de los productos amplificados se analizó a partir de 65 hasta $95^{\circ} \mathrm{C}$ con lectura de placa cada $0.3{ }^{\circ} \mathrm{C}$. Finalmente, los productos fueron conservados a $4{ }^{\circ} \mathrm{C}$. El software 7500 v. 2.0.1 analizó la curva de amplificación $(\mathrm{Ct})$ y la temperatura de disociación $(\mathrm{Tm})$ de los productos amplificados.

\section{Análisis de Expresión del ARNm}

Se usó el método comparativo $2^{-\Delta \Delta} \mathrm{Ct}$ (Livak y Schmittgen, 2001), empleando como calibrador el grupo de fetos de 11 meses de gestación ( $\mathrm{n}=3$ ) y como control endógeno el gen de Gliceraldehido-3-fosfato deshidrogenasa (GAPDH).

\section{Análisis Estadístico}

Se utilizó el análisis de varianza de un factor y la prueba post hoc de Bonferroni para evaluar los resultados del método comparativo $2^{-\Delta \Delta} \mathrm{Ct}$ para IL-10 y TGF- $\beta$ entre los tres grupos etarios, utilizando el programa STATA v. 11, con una significación estadística de 0.05 .

\section{Resultados}

Se analizó la expresión de ARNm del gen de GAPDH (usado como control endógeno), así como de los genes IL-10 y TGF- $\beta$, encontrando niveles detectables de ARNm en todas las muestras.

Los valores de la curva de disociación o temperatura de melting ( $\mathrm{Tm}$ ) de los productos amplificados mostraron un pico único en cada una de las muestras, presentando un 


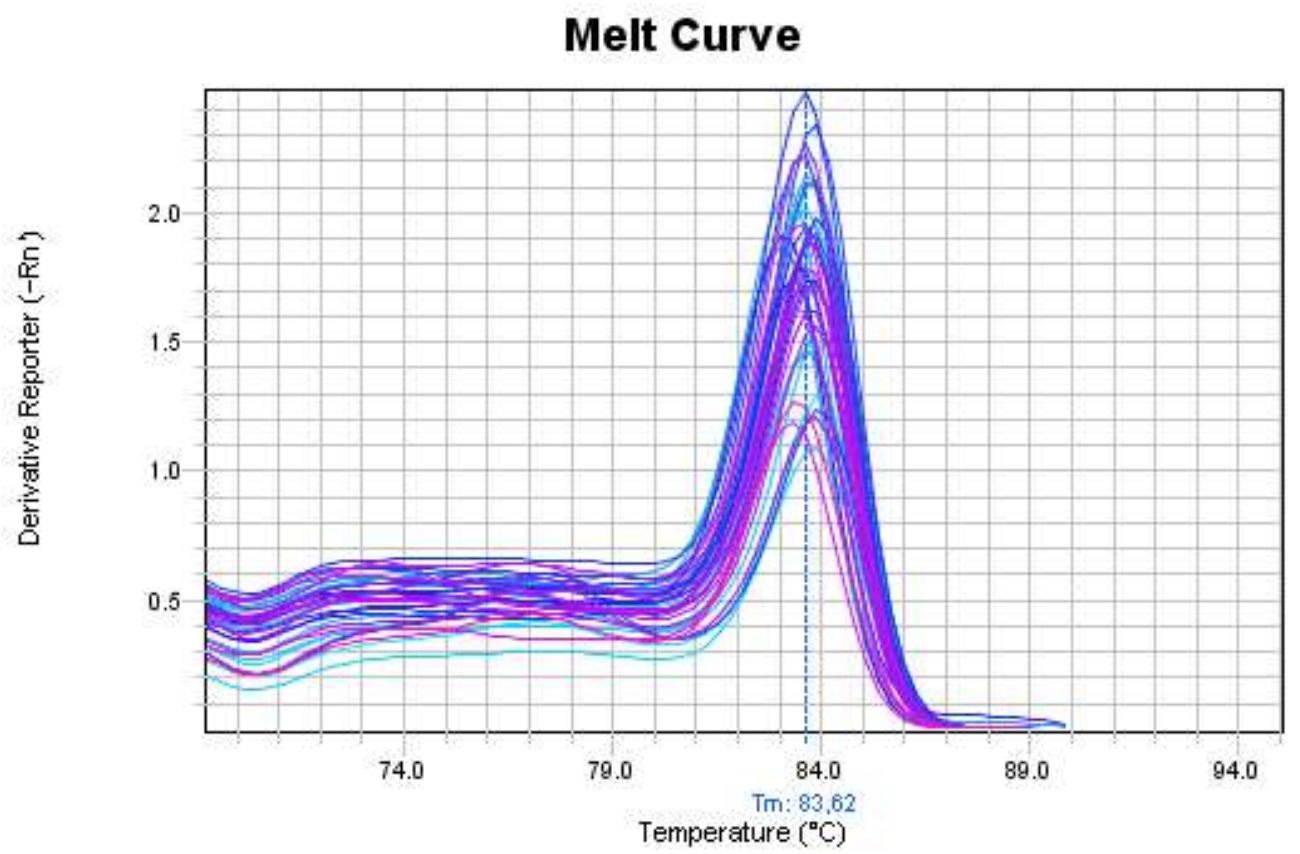

Figura 1. Curvas de disociación (Tm) de los productos amplificados con el set de oligonucleótidos para el gen IL-10 en mucosa intestinal de crías de alpaca sanas. Los valores de Tm oscilaron entre 83.1 y $83.8^{\circ} \mathrm{C}$

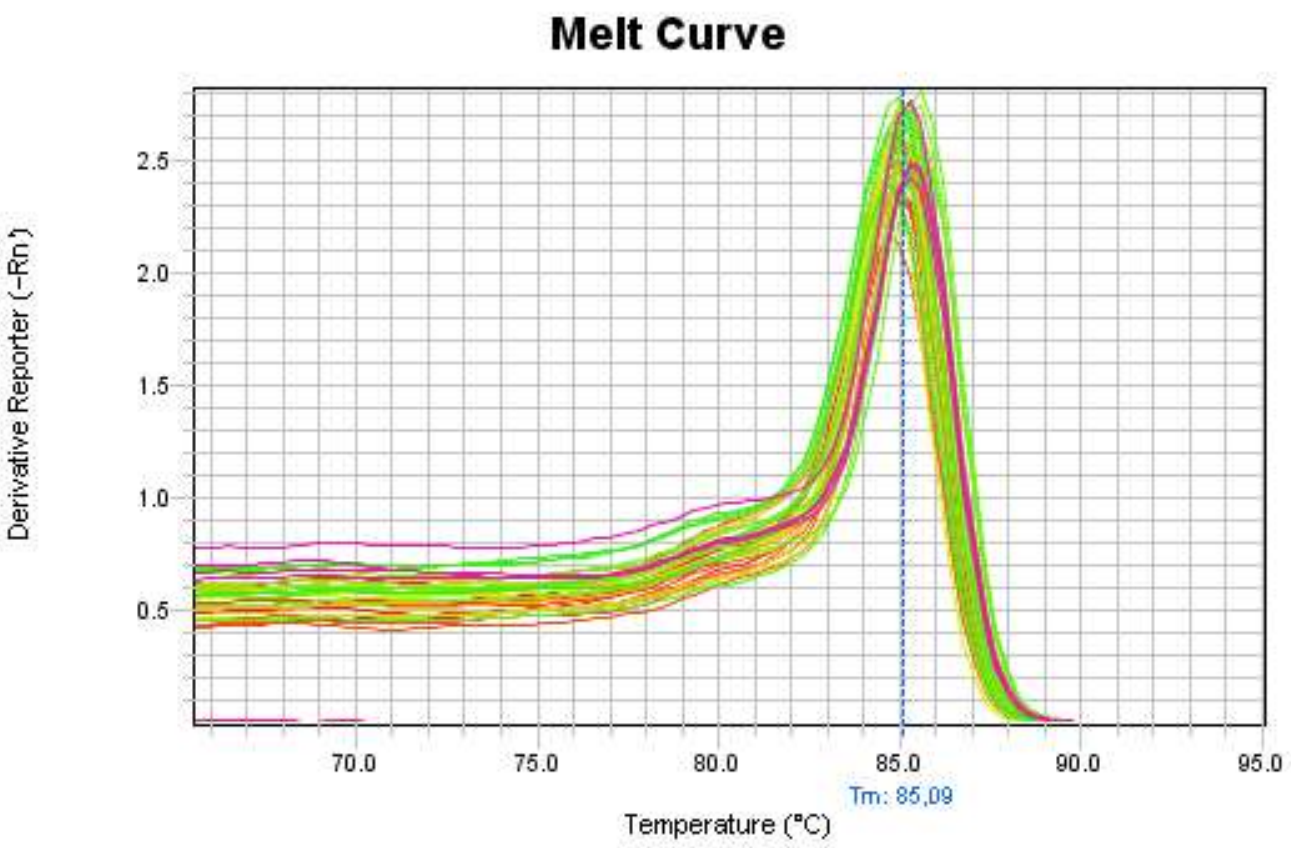

Figura 2. Curvas de disociación (Tm) de los productos amplificados con el set de oligonucleótidos para el gen TGF- $\beta$ en mucosa intestinal de crías de alpaca sanas. Los valores de Tm oscilaron entre 84.8 y $85.4^{\circ} \mathrm{C}$ 


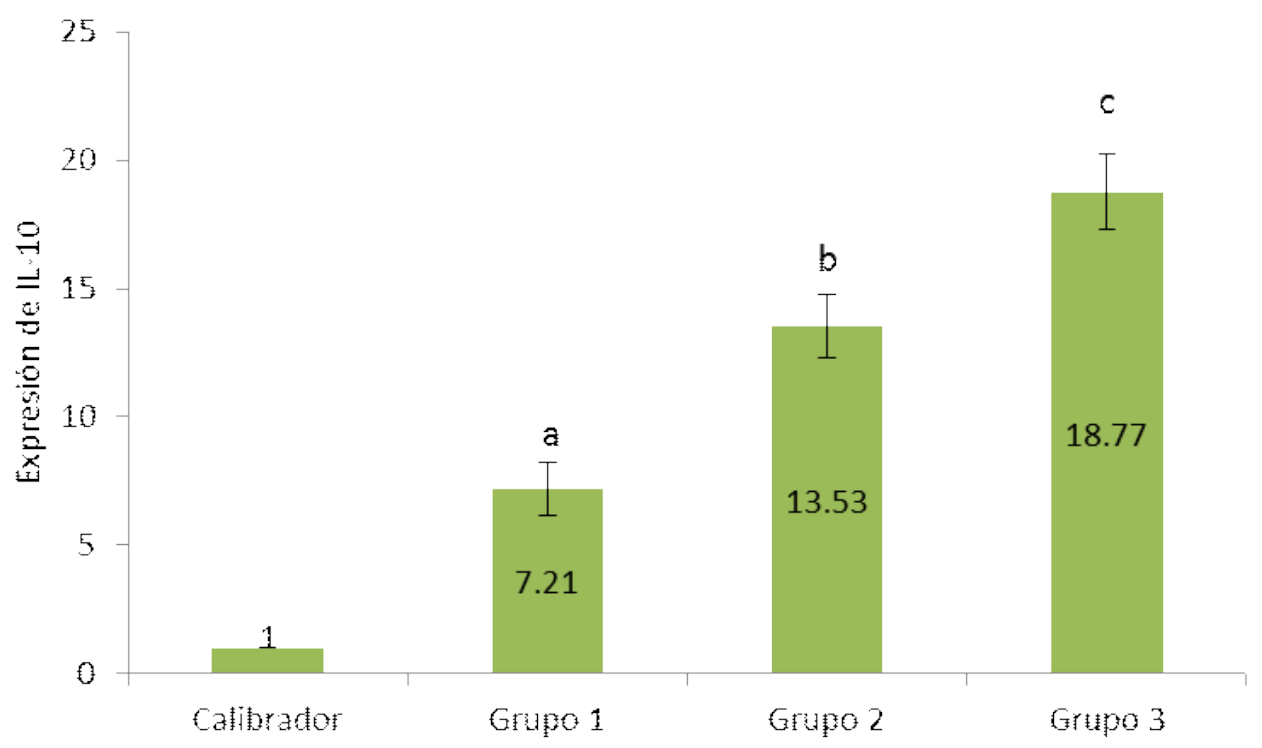

Figura 3. Niveles de expresión de IL-10 en mucosa intestinal de crías de alpaca sanas. Cada barra representa la media \pm desviación estándar de la expresión de los grupos etarios evaluados. Diferentes letras sobre las columnas indican diferencia estadística $(\mathrm{p}<0.05)$

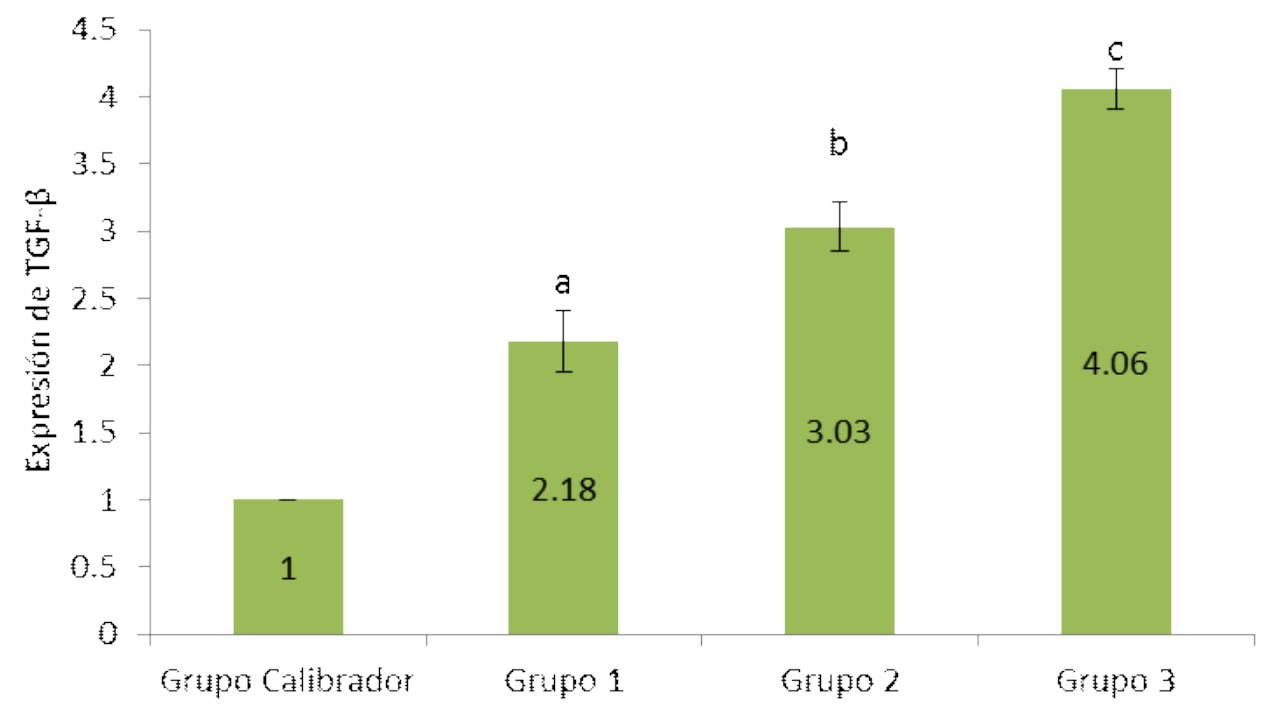

Figura 4. Niveles de expresión de TGF- $\beta$ en mucosa intestinal de crías de alpaca sanas. Cada barra representa la media \pm desviación estándar de la expresión de los grupos etarios evaluados. Diferentes letras sobre las columnas indican diferencia estadística $(p<0.05)$ 
rango de temperaturas que osciló entre 86 y $86.5^{\circ} \mathrm{C}$ para GAPDH, 83.1 y $83.8^{\circ} \mathrm{C}$ para IL-10 (Figura 1) y de 84.8 y $85.4{ }^{\circ} \mathrm{C}$ para TGF- $\beta$ (Figura 2), tal y como se predijo en el diseño de los cebadores, demostrando la amplificación de productos únicos y específicos.

Los resultados de la cuantificación relativa mostraron niveles de ARNm de IL-10 ascendentes con la edad, encontrando valores promedio de $7.21 \pm 1.02$ (grupo 1), 13.53 \pm 1.26 (grupo 2 ) y $18.77 \pm 1.48$ (grupo 3 ) veces lo expresado con respecto al grupo calibrador, mostrando diferencia significativa $(p<0.05)$ en todos los grupos (Figura 3$)$.

Los resultados de la cuantificación relativa mostraron niveles de ARNm de TGF$\beta$ ascendentes con la edad, encontrando valores promedio de $2.18 \pm 0.23$ (grupo 1), 3.03 \pm 0.18 (grupo 2) y $4.06 \pm 0.15$ (grupo 3 ) veces lo expresado con respecto al grupo calibrador, mostrando diferencia estadísticamente significativa $(\mathrm{p}<0.05)$ en todos los grupos (Figura 4).

\section{Discusión}

Los resultados muestran un incremento de la expresión de IL-10 y TGF- $\beta$ con la edad en la mucosa de yeyuno de las crías de alpaca. Ambas citoquinas regulan el proceso de colonización de la microbiota intestinal normal y el enfrentamiento a los patógenos presentes en su ambiente durante el periodo neonatal (Rojas et al., 2015). Además, se sabe que IL-10 reprime la expresión de muchas citoquinas pro-inflamatorias (Couper et al., 2008), regulando la respuesta inmune en procesos infecciosos, evitando que sean patológicas (Gazzinelli et al., 1996), y TGF- $\beta$ induce a las células del epitelio intestinal a reparar y restaurar los tejidos dañados en este órganos (Beck et al., 2003).

La expresión ascendente mostrada por IL-10 y TGF- $\beta$ se asocia a múltiples factores. El calostro contiene diversos elementos como anticuerpos, leucocitos, citoquinas y nutrientes que influyen en el desarrollo del sistema inmune y protección del neonato (Brown, 2000). La colonización de microorganismos en el intestino es necesaria para el desarrollo del sistema inmune intestinal (Lei et al., 2015); sin embargo, este sistema es constantemente retado por los patógenos del entorno (Rosadio et al., 2012) modificando la estructura y función de la mucosa intestinal. Cabe resaltar que las alpacas inician la ingesta de forraje en las primeras semanas de vida, efectuándose un cambio en la microbiota intestinal y en la respuesta inmune (Bailey et al., 2001). Además, al transcurrir las semanas, el intestino crece en su totalidad, aumentando el número de folículos linfoides y el número de leucocitos (Roca et al., 2014).

En otros estudios, las expresiones de TNF- $\alpha$, IL-1 $\alpha$ (Bardález et al., 2013), IL17 (Herrera, 2012), IgA (Dionisio et al., 2014) y péptidos anti-microbianos (More et al., 2011) en mucosa intestinal de crías de alpaca, muestran una fuerte respuesta inmune inicial en las primeras semanas de vida, alcanzando su máxima expresión en la $3^{\text {ra }}$ y $4^{\text {ta }}$ semana, lo cual se encuentra asociado a la colonización de la microbiota y a otros factores estimulantes previamente mencionados. Sin embargo, entre la $5^{\text {ta }}$ y $6^{\text {ta }}$ semana de vida se presenta un ligero descenso en la expresión de estas citoquinas y en los péptidos antimicrobianos, lo cual se asocia a una regulación y adaptación de las alpacas neonatas con su entorno (Bardález et al., 2013; Siuce et al., 2015). En contraste, las citoquinas en estudio muestran una expresión ascendente con la edad, aun en los animales de 26 a 47 días, sugiriendo que la actividad antiinflamatoria de IL-10 y TGF- $\beta$ regularía, tanto a la inmunidad innata como adquirida, en esta etapa de vida.

En este trabajo, las Tm de los productos amplificados variaron mínimamente y se les considera específicas por el reducido rango observado. Es posible que estas diferencias sean el resultado de las variaciones de lectura propias del termociclador o pequeñas fa- 
llas de la polimerasa en el proceso de polimerización de la cadena nucleotídica y que en los PCR tiempo real podría tener una variación de 6 a $37 \%$, con una mayor precisión con un mayor número de copias (Morrison et al., 1998). Por otro lado, no se pudo establecer la existencia de polimorfismos $\mathrm{o}$ isoformas procedentes de mecanismos de recombinación genética propia de la generación de los ARNm de las citoquinas estudiadas, aunque no se observaron productos que generen dos curvas de disociación en los resultados de cada muestra. Se requiere realizar el secuenciamiento nucleotídico de los productos del RT-PCR tiempo-real para la identificación de tales variaciones y emplear técnicas avanzadas para develar las implicancias de tales cambios (Gould-Rothber, 2001).

\section{Conclusiones}

- La expresión de ARNm de IL-10 y TGF$\beta$ en la mucosa de yeyuno de las crías de alpaca asciende progresivamente con la edad.

- Se demostró la presencia de ARNm de IL-10 y TGF- $\beta$ en la mucosa del yeyuno desde el $2^{\circ}$ día de edad a través de la técnica RT-PCR tiempo real.

\section{Agradecimientos}

Este trabajo fue financiado por el Programa de Innovación para la Competitividad y Productividad (INNÓVATE - Perú) a través del Proyecto N. ${ }^{\circ} 180$ FINCyT- IB -2013.

\section{Literatura Citada}

1. Ameghino E, De Martini J. 1991. Mortalidad en crías de alpacas. Bol Divulgación IVITA, UNMSM. Lima. 71p.

2. Bailey M, Plunkett FJ, Rothkötter HJ, Vega-Lopez MA, Haverson K, Stokes CR. 2001. Regulation of mucosal immune responses in effector sites. Proc
Nutr Soc 60: 427-435. doi: 10.1079/ PNS2001118

3. Bardález C, Manchego S, Chiok C, Lam K, Sandoval C, More B, Pezo D, Ramírez V. 2013. Cinética de expresión del factor de necrosis tumoral alfa (TNF$\alpha$ ) e interleucina 1 alfa (IL- $1 \alpha$ ) en mucosa intestinal de crías de alpaca (Vicugna pacos) sanas y con enteropatía. Rev Inv Vet Perú 24: 381389. doi: 10.15381/rivep.v24i3.2588

4. Beck PL, Rosenberg IM, Xavier RJ, Koh T, Wong JF, Podolsky DK. 2003. Transforming growth factor- $\beta$ mediates intestinal healing and susceptibility to injury in vitro and in vivo through epithelial cells. Am J Pathol 162: 597-608.

5. Biancheri P, Giuffrida P, Docena GH, MacDonald TT, Corazza GR, Di Sabatino A. 2014. The role of transforming growth factor (TGF) $-\beta$ in modulating the immune response and fibrogenesis in the gut. Cytokine Growth Factor Rev 25: 45-55. doi: 10.1016/ j.cytogfr.2013.11.001

6. Brown BW. 2000. A review on reproduction in South American camelids. Anim Reprod Sci 58: 169- 195. doi: 10.1016/S0378-4320(99)00081-0

7. Couper K, Blount D, Riley E. 2008. IL-10: the master regulator of immunity to infection. J Immunol 180: 5771-5777. doi: 10.4049/jimmunol.180.9.5771

8. Curotto de Lafaille MA, Lafaille JJ. 2009. Natural and adaptive foxp $3+$ regulatory T cells: more of the same or a division of labor? Immunity 30: 626635. doi: 10.1016/j.immuni.2009.05.002

9. Dionisio J, Manchego A, Chiok KL, Sandoval N, More J, Pezo D, Rivera H. 2014. Cinética de expresión de inmunoglobulina A en el epitelio intestinal de crías de alpaca (Vicugna pacos). Rev Inv Vet Perú 25: 151-161. doi: 10.15381/rivep.v25i2.8486

10. Gazzinelli RT, Wysocka M, Hieny S, Scharton-Kersten T, Cheever A, Kühn R, Müller W, Sher, A. 1996. In the absence of endogenous IL-10, mice 
acutely infected with Toxoplasma gondii succumb to a lethal immune response dependent on CD4+ T cells and accompanied by overproduction of IL12, IFN-gamma and TNF-alpha. J Immunol 157: 798-805.

11. Gould-Rothberg B. 2001. Mapping a role for SNPs in drug development. Nat Biotechnol. 19: 209-211. doi: 10.1038/ 85631

12. Harrison OJ, Powrie FM. 2013. Regulatory $\mathrm{T}$ cells and immune tolerance in the intestine. Cold Spring Harb Perspect Biol 5: a018341. doi: 10.1101/ cshperspect.a018341.

13. Herrera A. 2012. Detección de citoquinas inductora y efectora para la diferenciación y función de linfocitos colaboradores 17 (Th 17) en mucosa intestinal de crías de alpaca (Vicugna pacos). Tesis de Magíster. Lima: Univ Nacional Mayor de San Marcos. 90 p.

14. Konkel JE, Chen W. 2011. Balancing acts: the role of TGF- $\beta$ in the mucosal immune system. Trends Mol Med 17: 668-676. doi: 10.1016/j.molmed.2011.07.002

15. Lei YMK, Nair L, Alegre ML. 2015. The interplay between the intestinal microbiota and the immune system. Clin Res Hepatol Gastroenterol 39: 9-19. doi: 10.1016/j.clinre.2014.10.008

16. Livak KJ, Schmittgen TD. 2001. Analysis of relative gene expression data using real-time quantitative PCR and the $2^{-\Delta \Delta \mathrm{Ct}}$ method. Methods 25: 402-408. doi: 10.1006/meth.2001.1262

17. More J, Manchego A, Sandoval N, Ramírez M, Pezo D, Chiok KL, Rivera H. 2011. Detección genómica y expresión de péptidos antimicrobianos $(\alpha-$ y $\beta$-defensinas) en mucosa intestinal de crías de alpaca (Vicugna pacos). Rev Inv Vet Perú 22: 324-335. doi: 10.15381/ rivep.v22i4.332
18. Morrison TB, Weis JJ, Wittwer CT. 1998. Quantification of low-copy transcripts by continuous SYBR Green I monitoring during amplification. Biotechniques 24: 954-958, 960, 962.

19. Roca V, Manchego A, Sandoval N, Chiok KL, Rivera H. 2014. Caracterización histológica y dinámica linfoide de las placas de Peyer en crías de alpaca durante los 45 primeros días de vida. Rev Inv Vet Perú 25: 341-349. doi: 10.15381/ rivep.v25i3.10112

20. Rojas M, Manchego A, Rocha C, Fornells L, Silva R, Mendes G, Dias $G$, et al. 2015. Outbreak of diarrhea among preweaning alpacas (Vicugna pacos) in the southern Peruvian highland. J Infect Dev Ctries 10: 269274. doi: $10.3855 /$ jidc. 7398

21. Rosadio R, Maturrano L, Pérez D, Luna E. 2012. El complejo entérico neonatal en alpacas andinas. Rev Inv Vet Perú 23: 261-271. doi: 10.15381/ rivep.v23i3.908

22. Saraiva M, O'Garra A. 2010. The regulation of IL-10 production by immune cells. Nat Rev Immunol 10: 170-181. doi: 10.1038/nri2711

23. Siuce J, Manchego A, Sandoval N, More J, Chiok K, Pezo D, Rivera H. 2015. Expresión de defensinas en yeyuno de crías de alpacas (Vicugna pacos) con enteropatías. Rev Inv Vet Perú 26: 317-327. doi: 10.15381/ rivep.v26i2.11093

24. Spits H, de Waal Malefyt. R. 1992. Functional characterization of human IL10. Int Arch Allergy Immunol 99: 8-15.

25. Watanabe R, Manchego A, Rivera $H$. 2014. Expresión In vitro de las interleucinas 2 y 10 de linfocitos de alpacas (Vicugna pacos) en presencia de antígenos clostridiales. Rev Inv Vet Perú 25: 419-429. doi: 10.15381/ rivep.v25i3.10121 